\title{
Evidence-based policy on road safety: the effect of the demerit points system on seat belt use and health outcomes

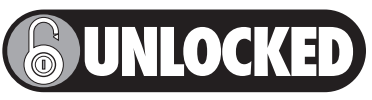

\author{
Francesco Zambon, Ugo Fedeli, Cristiana Visentin, Maria Marchesan, \\ Francesco Avossa, Stefano Brocco, Paolo Spolaore
}

This paper is freely available online under the BMJ Journals unlocked scheme, see http://jech.com/info/unlocked.dtl

J Epidemiol Community Health 2007;61:877-881. doi: 10.1136/jech.2006.057729

Objective: To assess the effect of a demerit points system, introduced in Italy in July 2003, on the prevalence of seat belt use (intermediate outcome) and the number of road traffic deaths and injuries (health outcomes).

Design: Pre- and post-intervention regional observational study for seat belt investigation (April 2003, October 2004); national time-series analysis of road traffic deaths and injuries between 1999 and 2004 for health outcomes.

Setting: Veneto region, Italy.

Participants: 19551 drivers, 19057 front passengers and 8123 rear passengers estimated to be aged over 11 years were included in the investigation into seat belt use. 38154 fatalities and 1938550 injured subjects were examined for the time-series analysis.

Interventions: Demerit points system.

Main outcome measures: The proportions of drivers and front and rear passengers observed to be using seat belts before and after the intervention; estimates of lives and injuries saved through the implementation of a penalty points system.

Results: The demerit points system was followed by an increase in observed seat belt use of $51.8 \%$ (95\% confidence interval $48.7 \%$ to $54.9 \%$ ) among drivers, of $42.3 \%$ (95\% confidence interval $39.2 \%$ to $45.5 \%$ ) among front passengers and of $120.7 \%$ (95\% confidence interval $99.4 \%$ to $144.3 \%$ ) among rear passengers. It is estimated that 1545 (95\% confidence interval 1387 to $1703 ; p<0.0001$ ) deaths and 91772 (95\% confidence interval 67762 to 115783 ; $\mathrm{p}<0.0001$ ) injuries were prevented in the 18 months after the introduction of the legislation, i.e. an $18 \%$ reduction $(1545 / 8570)$ in fatalities and a 19\% reduction (91 772/473 048) in injuries.

Conclusions: The demerit points system is effective both in encouraging drivers and passengers to adhere to the law and in terms of health outcomes, substantially contributing to road safety.

See end of article for authors' affiliations

Correspondence to:

Francesco Zambon, medical epidemiologist, Viale della Vittoria 83, Vittorio Veneto 31029, Italy; francesco.zambon@unipd.it

Accepted 9 March 2007

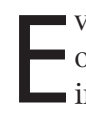
very year around 1.2 million people are killed on the world's roads and up to 50 million are injured or disabled as a result of traffic accidents. ${ }^{1}$ The global picture of the phenomenon is projected to worsen, with road traffic events estimated to become the sixth leading cause of death worldwide and to take third place as a cause of disability by 2020 . $^{2}$

The majority of preventative strategies and interventions that have been implemented to prevent road accidents are based on the theoretical foundation of Haddon's matrix, in which human, vehicle and environmental factors are supposed to interact in the pre-crash, crash and post-crash phases of a collision. ${ }^{3-5}$

Traffic law enforcement is mainly focused on human factors and, among the different strategies that have been implemented in this area, the demerit points system is a widely used punitive and educational measure. ${ }^{6}$ In this system, specific infractions of traffic regulations by drivers incur one or more licence penalty points in addition to a fine. When the number of points reaches a certain level, or if a driver commits certain severe offences, the driver's licence is suspended.

Despite their widespread use, the overall effect of penalty points systems on traffic safety in the short and long term remains controversial. ${ }^{7-10}$ Some authors claim that, paradoxically, traffic law enforcement may induce more risk-taking behaviours, ${ }^{11}$ and that the effect of a penalty system greatly varies depending on the context, sometimes leading to effects opposite to those intended. ${ }^{12}$

Furthermore, the evaluation of penalty points systems is associated with some major methodological difficulties. For example, any analysis needs to consider previous time trends and seasonal patterns. Furthermore, it is difficult to include a control group as such schemes are usually introduced at a national scale and it is rarely possible to attribute a clear causal role to these interventions. Nevertheless, there is an urgent need to fill this gap in our current knowledge as demerit points systems nay have important preventative benefits.

Among the different types of laws that can be implemented to increase traffic safety, most attention has been paid to seat belt legislation because of the huge potential benefits of such a safety measure. Various approaches have been taken to increase seat belt use. One of the most effective tools is to pass a law that makes the wearing of seat belts compulsory, with law enforcement being achieved by various means. ${ }^{13}$

Penalty points legislation was introduced in Italy in July 2003, with the goals of changing targeted behaviours, including seat belt use (intermediate outcome), and consequently reducing trafficrelated deaths and injuries (health outcomes). ${ }^{14}$ Under the new legislation, not wearing a seat belt is punishable by the imposition of licence penalty points and a fine (double that previously imposed). In addition, other offences, such as 
exceeding the speed limit by $40 \mathrm{~km} / \mathrm{h}$ or more, driving while impaired by alcohol or drugs, street racing and reversing on highways, incur a range of penalities up to immediate revocation of the driving licence. ${ }^{15}$

The new demerit points system received considerable attention in the national media. In addition, police officers were asked to be particularly vigilant to increase the perceived threat of being caught in case of an infringement.

In this study, we aimed to assess the level of compliance with the new law as regards seat belt use and to investigate whether introduction of new law was followed by a reduction in road traffic fatalities and injuries.

\section{MATERIALS AND METHODS}

The study was structured in two parts: a regional observational study to investigate the prevalence of seat belt use before and after the introduction of the penalty points system (on l July 2003) and a national time-series analysis to detect a change over time in the number of road traffic fatalities and injuries.

\section{Observational study}

Seat belt investigation was carried out in the Veneto region of north-east of Italy, which has a population of about 4.6 million, more than 3.5 million motor vehicles and a motorway/highway network of $10000 \mathrm{~km}$, and accounts for approximately $10 \%$ of all victims of road traffic accidents in Italy.

A pre- and post-intervention observational study (carried out in April 2003 and October 2004 respectively) assessed the prevalence of safety restraint use before and after the introduction of the demerit points system among drivers and front/rear passengers apparently aged over 11 years in cars, light trucks and vans. A multistage stratified sample was extracted following the sampling procedures established by the National Highway Traffic Safety Administration (NHTSA). ${ }^{16}$

The 580 municipalities of the region constituted the primary sampling units and were first grouped by the seven regional provinces. In the first stage of the sample selection, we included the seven provincial capitals plus a random selection of 15 municipalities with probability proportional to province population size. In the second stage, 20 road segments were randomly selected for each of the 22 sample municipalities, giving a total of 440 road segments. In the third stage, convenience sampling, guaranteeing the safety of observers and reliability of observations, was used to select observation sites within each road segment. Intersections regulated by traffic lights and highway tollbooths were chosen as observation locations, as at these locations it was possible to follow vehicles as they slowed or stopped, permitting accurate data collection.

Two observers were assigned to each observation site and recorded seat belt use in all vehicles passing the intersection or tollbooth until the number of predefined observations was achieved (21 drivers, 21 front passengers and eight rear passengers for each site).

The sample size was chosen to guarantee a margin of error of $\pm 1 \%$ at a $95 \%$ level of confidence (expected proportion of safety belt use $60 \%, 60 \%$ and $10 \%$ for driver, front and rear passenger respectively).

Emergency vehicles, such as ambulances and police cars, heavy trucks, buses and all vehicles with foreign number plates were excluded from the study.

The survey was carried out on weekdays from 08:00 to 18:00 h.

Observers participated in an intensive training, including classroom reviews of data collection procedures; a recording protocol was developed and given to each observer. Once a consistent standard of recording procedures had been achieved, as assessed by practical observation in different locations and settings, the observers were divided into pairs and each pair was assigned to one of the selected observation sites, where simultaneous observations were made.

To avoid recording information on the same vehicle more than once in each time period, observation periods were short and were carried out simultaneously in locations reasonably far away one another.

For each eligible vehicle, the observers recorded occupant position and safety belt use of subjects estimated to be aged over 11 years. Age could not be accurately determined without stopping vehicles and interviewing drivers and passengers, which would have posed potential risks to the observers as well as affecting the validity of the data collection by giving occupants time to fasten their seat belts.

Differences in the percentage of vehicle occupants who wore seat belts before and after the intervention were assessed using the chi-squared test.

\section{Time-series study}

We utilised data on road traffic crashes routinely collected by the police for the purpose of informing the Italian National Institute of Statistics. This data collection covers all crashes involving at least one vehicle and resulting in injury or death (within 30 days) of at least one person. ${ }^{17}$ We selected information on crashes occurring in Italy from 1 January 1999 to 31 December 2004, and considered fatalities and injuries to all road users, as it is hoped that any safety benefits will affect all road users and not just drivers and passengers directly affected by the new legislation.

We studied monthly time series through an autoregression integrated moving average (ARIMA) Box-Jenkins model. ${ }^{18}$ Such a technique takes into account any seasonal pattern, the downward/upward historical trend and related autocorrelations.

We analysed the time series to test the hypothesis that the enactment of the law would have a statistically significant impact on road traffic deaths and injuries by adding to the model an intervention variable dichotomised into the pre- and post-enactment period. Annual fuel consumption and the number of motor vehicles on the roads each year were introduced in the model as measures of traffic volume. ${ }^{19}$

We used the intervention parameter estimates to compute the number of deaths and injuries that would have occurred in the absence of the adoption of penalty points system.

We performed all analyses on SAS software, version $9 \cdot 1$.

\section{RESULTS}

\section{Observational study}

We observed a total of 19551 drivers, 19057 front passengers and 8123 rear passengers. Table 1 presents the distribution of vehicle occupants observed to be wearing seat belts by occupant position and by year.

Between 2003 and 2004, a change in seat belt use was observed among all categories of vehicle occupants $(p<0 \cdot 001)$, with an increase of $51.8 \%$ (95\% confidence interval (CI) $48.7 \%$ to $54.9 \%$ ) for drivers, $42.3 \%$ (95\% CI 39.2 to 45.5 ) for front passengers and $120.7 \%$ (95\% CI $99.4 \%$ to $144.3 \%$ ) for rear passengers.

The greatest absolute difference was registered for drivers, with the proportion wearing a seat belt increasing from $54.5 \%$ (95\% CI $53.5 \%$ to $55.5 \%$ ) in 2003 to $82.8 \%$ (95\% CI $82.0 \%$ to $83.5 \%)$ in 2004. Among rear passengers, the prevalence of compliant behaviour more than doubled over the observation period but was still three times lower than that reported for front passengers in 2004.

\section{Time-series study}

The number of people killed and injured showed different temporal trends from 1999 to 2004. Until 2003, the annual 
Table 1 Absolute and relative distribution of vehicle occupants observed to be wearing seat belts by occupant position in the vehicle and year, Veneto region, Italy, 200304 ?

\begin{tabular}{|c|c|c|c|c|c|c|}
\hline \multirow{2}{*}{$\begin{array}{l}\text { Occupant } \\
\text { position in the } \\
\text { vehicle }\end{array}$} & \multirow{2}{*}{$\begin{array}{l}\text { Wearing } \\
\text { seat belt }\end{array}$} & \multicolumn{2}{|l|}{2003} & \multicolumn{2}{|l|}{2004} & \multirow[b]{2}{*}{$\chi^{2}$} \\
\hline & & $n$ & $\%$ & $\mathbf{n}$ & $\%$ & \\
\hline \multirow[t]{2}{*}{ Driver } & Yes & 5300 & 54.5 & 8137 & 82.8 & \multirow[t]{2}{*}{$\mathrm{p}<0.0001$} \\
\hline & No & 4419 & 45.5 & 1695 & 17.2 & \\
\hline \multirow[t]{2}{*}{ Front passenger } & Yes & 5032 & 53.3 & 7301 & 75.9 & \multirow[t]{2}{*}{$\mathrm{p}<0.0001$} \\
\hline & No & 4404 & 46.7 & 2320 & 24.1 & \\
\hline \multirow[t]{2}{*}{ Rear passenger } & Yes & 458 & 11.2 & 1004 & 24.8 & \multirow[t]{2}{*}{$p<0.0001$} \\
\hline & No & 3617 & 88.8 & 3044 & 75.2 & \\
\hline
\end{tabular}

number of fatalities recorded was stationary, but after the adoption of the demerit points system it showed a dramatic downward trend (figure 1).

According to the ARIMA model $(2,1,0)$ reported in table 2, the intervention potentially saved the lives of 1545 people $(95 \%$ CI 1387 to 1703; $p<0.0001)$ in 18 months, which, as a proportion of the 8570 subjects killed in the same period, represents an $18 \%$ reduction in fatalities.

The time-series for the 1938550 injured subjects showed an upward trend before 2003 and a downward trend thereafter (figure 2). The latter finding was statistically consistent with the hypothesis that an exogenous intervention introduced in July 2003 effectively reduced the number of injured victims afterwards.

According to our ARIMA model $(2,0,0)(1,0,0)$, reported in table 2, injury was prevented in 91772 subjects (95\% CI 67762 to $115783 ; \mathrm{p}<0.0001$ ) during the 18 -month period after the new legislation came into force, which, as a proportion of the 473048 injuries observed over the period, corresponds to a reduction of $19 \%$.

Both outcomes show a seasonal pattern, with peaks usually in the summer and troughs consistently recorded during February.

\section{DISCUSSION}

\section{Statement of main findings}

The adoption of the penalty points system had an effect on both the intermediate ooutcomes and the health outcomes. The overall prevalence of seat belt use among all vehicle occupants increased in the region under study from $46 \%$ to
Table 2 Autoregression integrated moving average (ARIMA) Box-Jenkins analysis of number of people killed and injured in road traffic accidents in Italy, 1999-2004

\begin{tabular}{lccc}
\hline & $\begin{array}{l}\text { Parameter } \\
\text { value }\end{array}$ & $\begin{array}{l}\text { Standard } \\
\text { error }\end{array}$ & p-value \\
\hline Dead subjects: ARIMA(2,1,0) & & & \\
Seasonal autoregressive, lag 12 & -0.492 & -3.456 & 0.001 \\
Seasonal autoregressive, lag 24 & -0.468 & -3.251 & 0.002 \\
Fuel consumption parameter & $5.4 \times 10^{-6}$ & 0.894 & 0.375 \\
Vehicle on the road parameter & $-6.9 \times 10^{-4}$ & -0.491 & 0.625 \\
$\quad$ Intervention parameter & -85.835 & -4.482 & $<0.0001$ \\
Model variance & 1683.968 & - & \\
Akaike information criterion & 460.54 & - & - \\
Injured subjects: & & & \\
ARIMA(2,0,0)(1,0,0) & 0.604 & 0.108 & $<0.0001$ \\
Autoregressive, lag 1 & 0.218 & 0.107 & 0.045 \\
Autoregressive, lag 2 & 0.903 & 0.038 & $<0.0001$ \\
Seasonal autoregressive, lag 12 & $5.1 \times 10^{-4}$ & $51.9 \times 10^{-4}$ & 0.010 \\
Fuel consumption parameter & $5.4 \times 10^{-4}$ & $5.0 \times 10^{-4}$ & 0.285 \\
Vehicle on the road parameter & -5098.463 & 680.567 & $<0.0001$ \\
$\quad$ Intervention parameter & $1.1 \times 10^{6}$ & - & - \\
Model Variance & & - & - \\
Akaike information criterion & 1054.6 & & \\
\hline
\end{tabular}

$70 \%$, with more than four in five drivers complying with the new law.

The number of road traffic fatalities and injuries significantly declined after the adoption of the penalty points system, with a nationwide reduction in the first 18 months of $18 \%$ and $19 \%$ respectively.

\section{Comparison with other studies}

The demerit points system is a relatively new topic within the substantial body of scientific research on the evaluation of different types of law enforcement to make the roads safer.

Specifically, its effect on seat belt use has not been previously evaluated. Nevertheless, many studies have established that primary law, i.e. enabling police officers to impose penalties for not wearing a seat belt even when no other violation of traffic law has occurred, is the most effective measure in increasing the prevalence of seat belt use, resulting in an associated decrease in fatalities. ${ }^{13} 2021$

Our finding of a $25 \%$ increase in seat belt use among drivers and front passengers is consistent with figures observed in countries that have intoduced primary law from a state of having no law regarding seat belt use, ${ }^{21}$ despite the fact that in

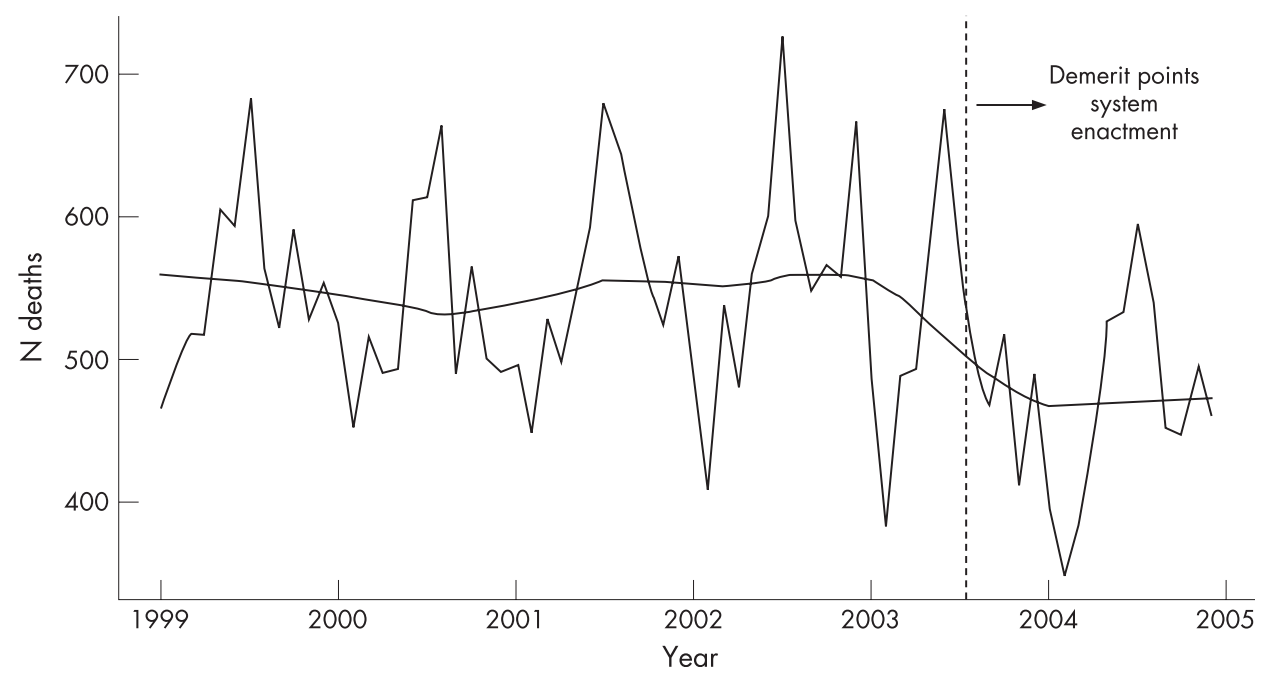

Figure 1 Number of people killed in road traffic crashes in Italy, by month, 1999$2004(n=38$ 154). 


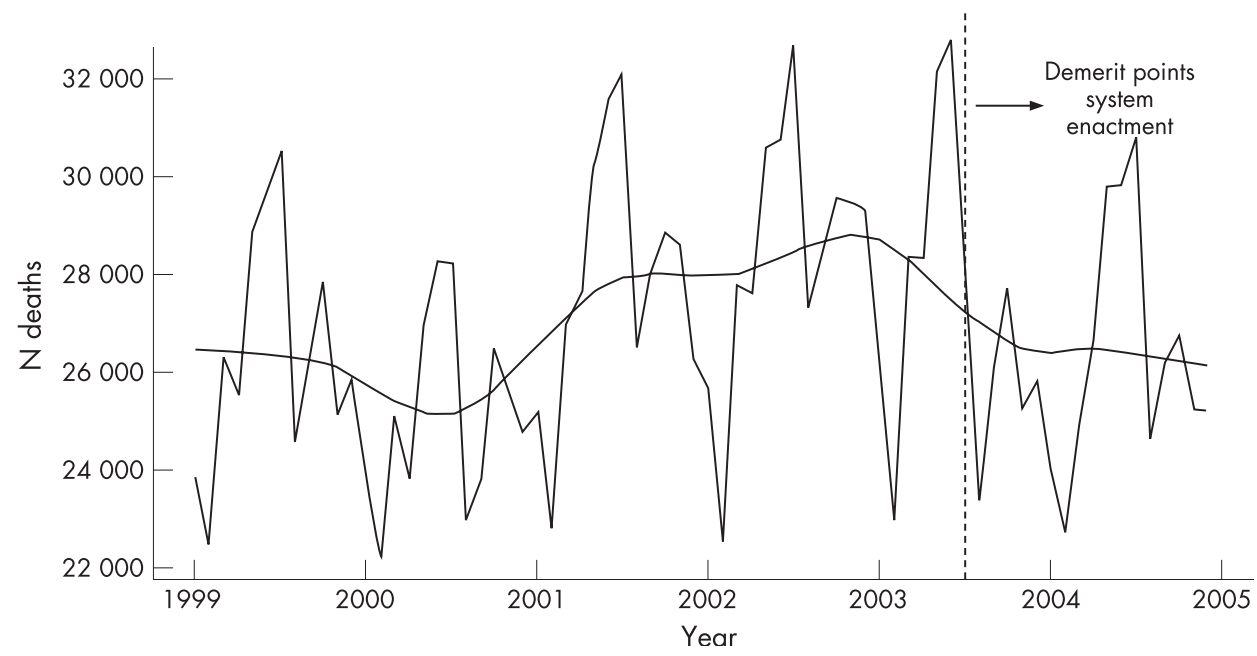

Figure 2 Number of people injured in road traffic accidents in Italy by month, 1999$2004(n=1938$ 660).

Italy the use of a seat belt has been mandated in primary law since 1989.

As a result of the introduction of the demerit points system, the prevalence of seat belt use in the Veneto region of Italy now appears to be higher than the average European Union (EU) rate of $76 \%$. Some EU member states have been successful in substantially increasing seat belt use by implementing different measures of traffic law enforcement. ${ }^{22}$ However, in Italy there remains considerable room for improving seat belt use among rear passengers, as the current rate of $25 \%$ is still considerably lower than the reported EU average of $46 \% .^{22}$ The poor adherence to legislation by rear passengers is of particular concern as it has been repeatedly shown that rear passengers who do not wear seat belts place both themselves and the front occupants at great risk of fatal injury in the event of a crash. ${ }^{23}$

As regards the effect of the new legislation on health outcomes, we observed a positive effect of the penalty points system on both injuries and fatalities, in agreement with the findings of other authors. ${ }^{74}$ The estimated $19 \%$ reduction in injuries observed in Italy is consistent with the $20 \%$ reduction in non-fatal injuries observed in the first 12 months after the introduction of the penalty points system in Ireland..$^{25}$ However, the $18 \%$ reduction in fatalaties recorded in Italy is generally lower than reported from other countries, where reductions of up to $25 \%$ have been observed in the first year after the introduction of similar measures of traffic law enforcement. ${ }^{82627}$

Our results, however, are not exactly comparable with previous studies evaluating the effect of a penalty points system, which typically have not taken into account either the historical trend or the seasonal pattern. Thus, other studies could have overestimated the effect of the penalty points system, as has been previously observed for seat belt legislation effectiveness. $^{28} 29$

Our reduction in fatalities is consistent with the finding of increased seat belt use, ${ }^{30}$ even taking into account the fact that the demerit points system is also used to penalise other major traffic law infractions. For example, severe speeding violations are punishable with licence withdrawal, and this is believed also to contribute to a reduction in road traffic accident mortality and injury. ${ }^{31}$

Although we found that the new leglislation was followed by positive effects on both the intermediate outcome and health outcomes, we cannot infer that the former caused the latter.

However, in contrast to previous findings ${ }^{8}$, we found that the overall reduction in fatalities and injuries was sustained in the first 18 months after the new legislation came into force.
Time-series analyses were also performed on a regional basis. The regional findings were consistent with the national results but were not statistically significant because of a high degree of variability, a large number of outlier values and low numbers of regional observations.

\section{Strengths and weaknesses of the study}

First, the technique used for time-series analysis overcame concerns related to historical trend and seasonality. ${ }^{31}$ Nevertheless, we did not control for variables other than fuel consumption and number of vehicles on the roads. As these variables did not change the estimated effect of the intervention, it is reasonable to assume that other independent timevarying variables, such as socioeconomic or technological factors, would have also had no effect on our models.

Second, although the findings of a seat belt investigation cannot be generalised to the whole of Italy, as a north-south gradient of seat belt use prevalence has previously been reported, ${ }^{32}$ we assumed that the introduction of the demerit points system resulted in a similar increase in the prevalence of seat belt use throughout the whole country. The observational study is susceptible to observer bias as the observers might expect to find more people wearing seat belts after the new law.

Furthermore, fatality data provided by the National Institute of Statistics, although guaranteeing homogeneity in collection throughout the national territory, are known to constantly underestimate the actual values; nevertheless, such a phenomenon should not bias temporal trends.

\section{What is already known on this subject}

- The demerit points system is a measure of traffic law enforcement widely used in many countries throughout the world.

- The effectiveness of the demerit points system in making the roads safer is controversial and not well supported by evidence.

- What this study adds

- The demerit points system significantly improves compliance with the legislation.

- The time trend of road traffic fatalities and injuries significantly declined after the adoption of the demerit points system. 
Finally, no other major interventions on road safety were carried out in the studied period, reducing history threats to internal validity.

\section{Implications for policy-makers}

The penalty points system appears to be an important opportunity to reduce road traffic victims, and thus calls for an optimal use, as few other preventative policies can have such massive and immediate consequences.

The penalty points system has important effects in terms of response to the law, and provides a substantial contribution to the reduction of traffic-related injury and mortality.

\section{ACKNOWLEDGEMENTS}

We thank all the local health agencies of the Veneto region and the health personnel who carried out the observational study. We thank all the staff of the Regional Centre for Epidemiology, who provided helpful support throughout the different phases of the study.

We would like to thank Professor Lucie Laflamme and Marie Hasselberg for their comments and valuable suggestions.

\section{Authors' affiliations}

Francesco Zambon, Ugo Fedeli, Cristiana Visentin, Maria Marchesan, Francesco Avossa, Stefano Brocco, Paolo Spolaore, Epidemiological Regional Centre, Veneto Region, Via Ospedale 18, 31033, Castelfranco, Veneto, Italy

Funding: National and Regional Health System.

Competing interests: None.

Ethics approval: Not required.

\section{REFERENCES}

1 Roberts I. War on the roads. BMJ 2002;324:1107-8.

2 Murray CJ, Lopez AD. Alternative projections of mortality and disability by cause 1990-2020: Global Burden of Disease Study. Lancet 1997;349:1498-504.

3 Haddon W. Advances in the epidemiology of injuries as a basis for public policy. Public Health Rep 1980;95:41 1-21.

4 US General Accounting Office. Factors contributing to traffic crashes and NHTSA's efforts to address them. Statement of Peter Guerrero, Director, Physical Infrastructure Issues. Washington, DC: US General Accounting Office, 2003 (GAO-03-730T). www.gao.gov/new.items/d03730t.pdf (accessed 5 June 2006).

5 Farland RA, Moore RC. Human factors in highway safety: a review and evaluation. N Engl J Med 1957;256:792-8.

6 European Transport Safety Council (ETSC) Traffic law enforcement across the EU - an overview. Brussels: ETSC, 2006. www.etsc.be/documents/ EU\%20Overview.pdf (accessed 5 September 2006).

7 Chipman ML, Morgan P. The role of driver demerit points and age in the prediction of motor vehicle collisions. Br J Prev Soc Med 1975;29:190-5.
8 Butler JS, Burke JP, Healy DG, et al. Trends in RTA related spinal injuries: the post penalty points era. Ir J Med Sci 2006;175:20-3.

9 Donnelly M, Murray P, Cleary S. Changes in trauma service workload since the introduction of the penalty points system. Ir Med J 2005;98:53-4.

10 Diamantopoulou K, Cameron M, Dyte D, et al. The relationship between demerit points accrual and crash involvement, Monash University Accident Research Centre. Report no.116, 1997. http://www.monash.edu.au/muarc/reports/ muarcl 16.html (accessed 28 February 2007).

11 Peltzman S. The effects of automobile safety regulation. J Polit Econ 1975;83:677-725.

12 Hijar M, Trostle JA. Letter Traffic law enforcement and safety. Lancet 2003;362:833.

13 Rivara FP, Thompson DC, Cummings P. Effectiveness of primary and secondary enforced seat belt laws. Am J Prev Med 1999;16:30-38.

14 Dinh-Zarr TB, Sleet DA, Shults RA, et al. Reviews of evidence regarding interventions to increase the use of safety belts. Am J Prev Med 2001;21:48-65

15 Italian Government. Decreto Legge 27 Giugno 2003, no. 151. Modifiche ed integrazioni al codice della strada. Italian Official Bulletin no. 149, 30 June 2003 (in Italian). www.parlamento.it/parlam/leggi/decreti/03151d.htm (Accessed 20 February 2007).

16 National Highway Traffic Safety Administration (NHTSA). Uniform criteria for state observational surveys of seat belt use, 23 CFR Part 1340 (Docket No. NHTSA-98-4280) RIN 2127-AH46, 1998. www.nhtsa.dot.gov/nhtsa/whatsup/ tea21/tea21 programs/surveyrule.ifr.html (accessed January 2003)

17 Italian National Institute of Statistics (ISTAT). Statistica degli incidenti stradali. Anni 2003-2004. www.istat.it/dati/catalogo/20051013_00//accessed 5 June 2006).

18 Scott PP. Modelling time-series of British road accident data. Accid Anal Prev 1986;18:109-17.

19 Cardoso JL. The use of international data on fuel sales and vehicle fleet for the estimation of yearly national traffic volumes. Accid Anal Prev 2005;37:207-15.

20 Farmer CM, Williams AF. Effect on fatality risk of changing from secondary to primary seat belt enforcement. J Safety Res 2005;36:189-94.

21 Shults RA, Elder RW, Sleet DA, et al. Primary enforcement seat belt laws are effective even in the face of rising belt use rates. Accid Anal Prev 2004;36:491-3.

22 European Transport Safety Council (ETSC). Cost effective EU transport safety measures. Brussels: ETSC, 2003. www.etsc.be/oldsite/costeff.pdf laccessed 20 July 2006).

23 Mayrose J, Jehle D, Hayes $M$, et al. Influence of the unbelted rear-seat passenger on driver mortality: "the backseat bullet". Acad Emerg Med 2005;12:130-4.

24 Redelmeier DA, Tibshirani RJ, Evans L. Traffic-law enforcement and risk of death from motor-vehicle crashes: case-crossover study. Lancet 2003;361:2177-82.

25 Lenehan B, Street J, Barry K, et al. Immediate impact of 'penalty points legislation' on acute hospital trauma services. Injury 2005;36:912-16.

26 Healy DG, Connolly P, Stephens MM, et al. Speed and spinal injuries. Injury 2004;35:908-12.

27 Poli de Figueiredo LF, Rasslan S, Bruscagin V, et al. Increases in fines and driver licence withdrawal have effectively reduced immediate deaths from trauma on Brazilian roads: first-year report on the new traffic code. Injury 2001;32:91-4.

28 Dee TS. Reconsidering the effects of seat belt laws and their enforcement status. Accid Anal Prev 1998;30:1-10.

29 Richens J, Imrie J, Copas A. Condoms and seat belts: the parallels and the lessons. Lancet 2000;355:400-3.

30 Evans L. The effectiveness of safety belts in preventing fatalities. Accid Anal Prev $1986 ; 18: 229-41$.

31 Masten SV, Hagge RA. Evaluation of California's graduated driver licensing program. J Safety Res 2004;35:523-35.

32 Taggi F, Di Cristofaro Longo G. I dati socio-sanitari della sicurezza stradale Progetto DATIS. Rome: Istituto Superiore di Sanità, 2001. 